\title{
GCU
}

Glasgow Caledonian

University

University for the Common Good

\section{Integrating early refresher practice in height safety and rescue training}

Lawani, Kenneth; Hare, Billy; Cameron, Iain

Published in:

Safety Science

DOI:

10.1016/j.ssci.2018.03.029

Publication date:

2018

Document Version

Author accepted manuscript

Link to publication in ResearchOnline

Citation for published version (Harvard):

Lawani, K, Hare, B \& Cameron, I 2018, 'Integrating early refresher practice in height safety and rescue training', Safety Science, vol. 110, no. A, pp. 411-417. https://doi.org/10.1016/j.ssci.2018.03.029

\section{General rights}

Copyright and moral rights for the publications made accessible in the public portal are retained by the authors and/or other copyright owners and it is a condition of accessing publications that users recognise and abide by the legal requirements associated with these rights.

Take down policy

If you believe that this document breaches copyright please view our takedown policy at https://edshare.gcu.ac.uk/id/eprint/5179 for details of how to contact us. 


\section{INTEGRATING EARLY REFRESHER PRACTICE IN HEIGHT SAFETY AND RESCUE TRAINING}

\section{ABSTRACT}

The non-routine practice of wind turbine height safety and rescue skills after training has significant impact on the competency and health and safety of construction and maintenance technicians. The proposition is that wind technicians who undertake initial training without practically carrying out hands-on rescue roles are most likely to forget the procedural steps during emergencies except there is an early refresher practice integrated within the system. Longitudinal study of 30 (subsample) wind technicians using Job Knowledge Test (JKT), hands-on practice test with Situational Judgment Test (SJT) and pictograph of the rescue device was employed. While the level of performance of wind technicians improved during acquisition, there was observed decline in performances over one and three month non-practice intervals. This confirms the significance of integrating early refresher practice of rescue and evacuation skills and the factors influencing the competence of the technicians over these timescale. To improve the competency of technicians and reduce the risk of injury or failed rescue, actual timescales have been identified showing that early refresher practice should be undertaken at three months after acquisition for returning technicians and within one month for new technicians.

Keyword: Wind technician, wind turbine, Job Knowledge Test, Situational Judgment Test, Wind Turbines Standards

\section{INTRODUCTION}

The significance of real-time rescue for wind technicians working on onshore and offshore wind farms cannot be overstated. Over the last 12 months, there has been series of fatal wind turbine related accidents resulting from falls from height (two within a month in Scotland) and this calls for an evaluation of refresher trainings associated with working at height on a wind turbine.

The integration of early refresher practice has been identified as potential solution to problems of skills and knowledge retention. This is very relevant in situations where individuals undergo training and end up not using or practicing such skills after a period of time (Arthur et al. 2007; Arthur Jr, et al. 2010; Kluge \& Frank 2014; Arthur Jr, et al. 2013). There are job requirements that necessitate certain groups of workers to undergo certain types of trainings as part of the employment strategy in scenarios where the workers do not have the opportunity to perform such skills over a period of time. Without comprehensive evaluation of practice and performance, determining skill decay and initiating early refresher practice for wind technicians is not practical.

The technicians generally undergo the basic level height safety and rescue training endorsed by RenewableUK (RUK) and the Global Wind Organisation (GWO), the main renewable 
energy trade association responsible for developing training standards to enhance the basic skills and knowledge of anyone working in the renewable energy sector. The work at height and rescue - Wind Turbines Standards (WTS) outlines the basic safety training and competence recommended for all personnel involved in working at height on wind turbines. This was achieved in consultation with members and key stakeholders endorsing benchmark standards, which incorporate the Global Wind Organisation (GWO) requirements. Though past research has highlighted the significance of refresher training, there is, however, considerable disagreement concerning the appropriate content and frequency of such training, (Teachout et al. 1993; Paulin et al. 2002).

The existing basic work at height and rescue training regarding use of rescue and evacuation devices on a wind turbine is adequate enough to attain some level of proficiency at the end of the training. However, the likelihood of wind technicians retaining such skill and knowledge up to a period of 24 months before embarking on formal refresher training has not been supported with evidence by the responsible organisation. Also, the competency of technicians to procedurally execute such skills in an emergency situation is paramount if there are no existing support services in place to aid the retention of the basic skills after periods of non-routine practice. Therefore, managing the safety and health of these technicians require some evidence to determine the pattern of decay of their skills and knowledge. This study examines part of the wider issue of 'work at height' which is one of the most fatal and high risk work activities associated with construction and maintenance workers.

The application of this study is not limited to only wind turbine rescue safety but also to other high hazard industries. Industries like construction involved in the use of mobile elevated work platforms (MEWPs) recorded two fatalities because an initial crush was compounded by a colleagues' inability to use the emergency lowering controls. Also, a review of the cause of explosion on the Rough 47/3-B gas storage installation operated by Centrica Storage in the North Sea in 2006 revealed that the lifeboat coxswain were unable to procedurally execute the specific steps needed to launch the lifeboat on the Rough installation. Therefore, this study can potentially inform rescue equipment designers and manufacturers in identifying and reducing strategic signs of forgetting effects by introducing cues or prompts; man-machine interaction modalities (a particular way of doing or experiencing something); error correction strategies; and instructions in the design of equipment focusing on elements of the recue or evacuation tasks that are most critical. These are especially important for 'low frequency high impact' (emergency) scenarios e.g. in associated industries like telecommunications, industrial climbing \& rigging, scaffolding, and tower crane which use rescue devices and are prone to similar retention of rescue skills. The integration of early refresher practice can enable the management to tailor resources and personalise some aspects of training to meet the required needs of workers (employees, 
self-employed and agency workers) rather than the generic training that is not always beneficial to all.

\section{SCOPE OF STUDY}

Wind technicians generally undergo a two-day work at height and rescue training which deals with safety critical skills and knowledge. Also, there is little or no training provided during intervals of non-practice and such acquired skills and knowledge for rescue and evacuation can be forgotten with the passage of time. Such forgetting can result in performance decline. Studies have also shown that practice of a task translates into procedural knowledge which leads to the acceleration of skilled performance, (Anderson 1983; Kluge et al. 2010; Kim et al. 2013) and that complex skills with limited workplace practice can degrade over a period of hours, days, weeks or months of non-practice.

The training the technicians undergo cover aspects such as dangers of working at height; how to assess the hazards and implement effective controls; how to use restraint, positioning and fall arrest systems; selecting proper anchor points; practical climbing on ladders using fixed vertical safety systems; recognising and dealing with suspension trauma; planning for emergency procedures; features and limitations of the rescue equipment being used; and how to rescue a suspended colleague from an in-reach and out-of-reach situation.

This paper focuses on the discrete procedural skills necessary for safe rescue of wind technicians during emergencies. The study investigates the impact of not integrating early refresher practice of rescue and evacuation skills within a period of one and three months. Also, the adopted training model for technicians implicitly assumes that technicians are capable of retaining the height safety and rescue skills over a period of two years but there is no published support for this assumption which this study considers unsustainable.

For every wind technician that has undergone the basic work at height safety; rescue and evacuation training; they are deemed fit to act as the first responders in emergency situations whilst working on any onshore or offshore wind farm. Therefore, determining the magnitude of their skill retention in using the rescue devices and initiating a safe evacuation plan is paramount. Also, the potential opportunities for technicians to embark on a refresher training in order to improve safety, proficiency and skill reliability after training is still lacking. Therefore, this process of investigating rescue and evacuation skills and knowledge will objectively provide relevant planning information on how much technicians learn and forget, thereby allowing for effective planning of training regimes.

The simple proposition is that when a wind technician undergoes training, their proficiency increases; in the absence of training and practice, proficiency declines. This study recommends refresher practice when technicians execute rescue skills below a set limit state performance', and to also identify when their proficiency is within its 'peak allowable 
performance'. Using this method, routine reviews of proficiency testing by employers will alert them to subtle shifts that might impact on output and embark on training employees that are underperforming in terms of safety, consistency in rescue procedures, accuracy and timeliness which are priorities during emergency rescues.

\subsection{Practice/Performance:}

Practice is the physical act or mental rehearsal of a task undertaken with the implicit or explicit goal of attaining some level of proficiency in performing that task, (Cannon-Bowers et al. 1998). Evidence suggests that for a successful transfer of training, technicians need both the resources and available opportunities to practice and perform the newly acquired skills (Clarke 2002; Salas et al. 2006; Burke \& Hutchins 2007; Weissbein et al. 2010). Practice supports the procedural learning of skills by knowledge compilation which eventually translates declarative knowledge into procedural knowledge (Anderson 1983; Kim et al. 2013) leading to the acceleration of skilled performance. Kluge et al. (2010) showed that practice improves skill retention; although this statement seems to be common sense, it has not been systematically investigated in comparison to other dynamic tasks such as height safety, rescue and evacuation for wind technicians.

There are several theories which advance the power law of practice (Newell \& Rosenbloom 1981; Delaney et al. 1998; Lee \& Anderson 2001). Anderson (1993) claims that the speed up is due to two mechanisms: knowledge is converted from a slow format (declarative knowledge) into a fast format (procedural knowledge) and the speed of individual pieces of procedural knowledge also increases with practice. Logan (1988) stated that with considerable practice, perceptual-motor skills can sometimes become automatic and that automatic processing is fast, effortless, and autonomous. In contrast, Carlson et al. (1990) stated that skill as a whole never become as automatic as driving one's car despite considerable practice. In summary, the amount of previous practice is directly related to an individual's current potential performance.

The degree to which the task environment can change while technicians plan and execute a rescue and evacuation activity and the range of possible actions are fairly unpredictable while working at height. However, the relationship between deliberate practice and performance would generally be more positive for high-predictability activities than for lowpredictability activities based on the notion that effects of training and deliberate practice on performance are stronger when the task environment is more predictable, see (Macnamara, et al., 2014).

\subsection{Training}

There is agreement that the single most important contributing factor of both skill and knowledge retention is the depth or amount of initial training or acquisition, (Weissbein et 
al. 2010; Cameron et al. 2011; Hatala et al. 2014). Hare \& Cameron (2011) reflected on the fact that the extent of safety training or qualification is expected to be a significant factor in relation to competence but however, no previous research has confirmed this link with training levels. Also, literature does not holistically offer an understanding of how best to abridge the loss of relevant skills in the absence of regular schedules of refresher training. However, it is understood that training can be enhanced by the instructor or system through the provision of supplementary cueing, feedback which leads to feedforward and the specification of the instructional facilities.

\section{STUDY APPROACH}

This study adopted a longitudinal research method consisting of a minimum of three repeated measures on wind technicians considered as the substantive constructs of interest, (Ployhart \& Vandenberg, 2010). There is little consensus, either in theory or practice regarding the best methods for the interpretation of longitudinal change. However, this measurement of longitudinal change was considered critical for understanding the process of skill and knowledge decay of wind technicians.

Primary data for this study was gathered using Job Knowledge Test (JKT), (Teachout et al. 1993; Paulin 2002) and hands-on direct observation with Situational Judgment Test (SJT), (Lievens et al. 2008; Patterson et al. 2016) using 2D images of the rescue equipment for both knowledge and skill. JKT represents one common and efficient way of assessing domain-specific knowledge (Lievens \& Patterson 2011) as they are often used to determine knowledge of facts, rules and principles and are primarily a measure of declarative knowledge. SJT on the other hand can be considered as a step removed from direct observation and are better viewed as measures of procedural knowledge in a specific domain, (Lievens \& Sackett 2012). The SJT was presented to the technicians using 2D images of the rescue equipment with written descriptions of how to use the equipment to carry out a rescue. The technicians were required to procedurally indicate how to use the stepwise guide to re-enact rescue of a casualty during an emergency situation from the list of predetermined responses provided (McDaniel et al. 2007; Weekley et al. 2006). The SJT was implemented as a low-fidelity simulation alternative to the traditional high-fidelity simulations, (Motowidlo et al. 1990; Anderson et al. 2017).

\section{THE PARTICIPANTS}

This study had a total of 30 wind technicians with varying years of practical experience (zero to $>10$ years) which fairly represents the wider technician population which this paper may wish to extrapolate. The author adopted a timeframe of one and three months based on research that non-routine complex procedural tasks are highly subject to forgetting after a relatively short period of non-practice, (Wixted \& Ebbesen 1991; Wixted 2004). Also, there are no standardised timeframe set out for the evaluation of skill retention as observed in 
the works of (Shields et al. 1979; Goldberg et al. 1981; Schendel \& Hagman 1982; Sauer et al. 2000; Arthur Jr. et al. 2002; Kim et al. 2007; Meador \& Hill 2011) which signifies that evaluations are established on individual capability. Based on the peripatetic nature of the wind technicians involved in this study and the generally acceptable refresher timeframe of two years, the author objectively adopted an early refresher timeframe of one and three months cognizant that within this timeframe, technicians would not have embarked on any height safety, rescue and evacuation trainings, practices or drills after formal training.

Within the construction and maintenance industry where there are requirements for workers to work at height, employers can provide workers (i.e. employees, self-employed and agency/casual) with any kind of rescue devices. This can possibly impede the performance of rescue activities if workers are not acquainted with the particular rescue device being used by the specific organisations. Also, due to the temporary and interdisciplinary nature of most construction and maintenance projects, the industry is often characterised by groups of workers that are peripatetic, unacquainted, working together over a limited period of time before disbanding to work on other projects, (Dainty et al. 2006). Therefore, such workers tend to lack the requisite learning and performance that are facilitated by response or feedback, and this can directly impact their capabilities. However, organisations with stable workforce tend to thrive better in terms of skill and knowledge retention due to some predictive elements of co-worker knowledge, team tenure, coworker and supervisory support, group orientation and group cohesion, see (Burt et al. 2008). This can potentially influence a worker's intellectual growth, learning, curiosity and engagement in productive instructional activities (Hirumi 2002). Employers are most likely to engage more with a stable workforce in terms of initiating regular training than with casual workforce such as agency workers or subcontractors. Therefore, initiatives such as workforce engagement for the improvement of OSH performance can make a desirable change for workers e.g. management engaging both employees and casual workforce throughout the various stages of a construction or maintenance project.

\section{DATA COLLECTION}

\subsection{Procedure}

A total of three knowledge assessments were conducted - two assessments in Day-1 (one pre-acquisition and acquisition) and one assessment in Day-2 (peak acquisition). Two handson skill assessments were conducted in both Day-1 (pre-acquisition) and Day-2 (acquisition) on wind technicians undergoing the height and rescue training programme. The retention intervals indicate the period that technicians have not put their knowledge and skills to use, i.e. at one and three months after training. These assessments were modelled after the renewable energy trade association approved tests for Work at Height \& Rescue Training Wind Turbines. Each question was scrutinised for validity/reliability before they were 
included in the final assessment, (Trochim 2005; Farrell 2011). The skill and knowledge retention assessments required technicians to correctly identify the rescue steps and accomplish the evacuation task.

\subsection{Piloting the height safety and rescue training test}

The design of the knowledge and skill assessments was modelled for assessing safety, competence, and aptitude during practical work. The height safety \& rescue assessment for knowledge incorporated major areas of training such as the elements of a safe system of work, equipment selection and inspection, use of tools, risk assessment, method statements and emergency procedures. The technicians were assessed on enactment and proficiency which necessitated them to act correctly within limit (Stothard \& Nicholson 2001; Sabol \& Wisher 2001). A cumulative point system was adopted for every correct step undertaken by the technicians and the data collected analysed using IBM Statistical Package for Social Science (SPSS) Statistics 21 to evaluate the reliability of the questionnaires and pairedsamples t-test.

\section{RESULTS}

\subsection{Interpretation of Output from Paired-Samples T-Test for Skill Assessment}

Paired-samples t-test was used in comparing the mean scores (Table 1) for the technicians (same group of people) on two different occasions of continuous measures at acquisition time $T_{1}$ versus one month retention $T_{2}$; one month retention $T_{2}$ versus three months retention $T_{3}$. This involved evaluating the changes in participants' skill retention test scores following participation at one month and three months assessments.

Table 1: Mean skill performance score for 30 technicians

\begin{tabular}{|l|r|r|r|}
\hline Skill Test Score & Mean & Std. Deviation & N \\
\hline $\mathrm{T}_{0}$ pre-acquisition @ day 1 & 14 & 26.987 & 30 \\
$\mathrm{~T}_{1}$ acquisition @ day 2 & 83.33 & 11.012 & 30 \\
$\mathrm{~T}_{2}$ retention @ 1 month & 68.67 & 22.397 & 30 \\
$\mathrm{~T}_{3}$ retention @ 3 months & 61.33 & 28.374 & 30 \\
\hline
\end{tabular}

The paired-samples t-test was conducted to evaluate the impact of non-practice on technicians' skill retention from Time $T_{1}$ during acquisition of skills $(M=83.33, S D=11.012$ ) to Time $T_{2}$ during one month retention $(M=68.67, S D=22.397), t(29)=4.144$, Sig. (p) $0.00<$ 0.05 (two-tailed). The mean difference in skill retention test score was 14.667 with a $95 \%$ confidence interval ranging from 7.428 to 21.905 , see Table 2 . The eta squared statistics of 0.372 indicated a large effect size using guidelines proposed by Pallant (2011) for interpreting this value, see Table 3. 
A paired-samples t-test was conducted to evaluate the impact of non-practice on the technicians' skill retention test scores from retention Time $T_{2}$ at one month $(M=68.67, S D=$ 22.40) to retention Time $T_{3}$ at three months $(M=61.33, S D=28.40), t(29)=1.803$, Sig. $(p)$ $0.082>0.05$ (two-tailed). The mean difference in skill retention test score was 7.33 with a $95 \%$ confidence interval ranging from -0.984 to 15.650 , see Table 2 . The eta squared statistics of 0.101 indicate a moderate effect size using guidelines proposed by Pallant (2011) for interpreting this value, see Table 3.

Table 2: Paired Samples Test for Skill Assessment

\begin{tabular}{|c|c|c|c|c|c|c|c|c|c|}
\hline & \multicolumn{5}{|c|}{ Paired Differences } & \multirow[t]{3}{*}{$\mathrm{t}$} & \multirow[t]{3}{*}{$\mathrm{df}$} & \multirow{3}{*}{$\begin{array}{l}\text { Sig. (2- } \\
\text { tailed) }\end{array}$} \\
\hline & & \multirow[t]{2}{*}{ Mean } & \multirow[t]{2}{*}{$\begin{array}{c}\text { Std. } \\
\text { Deviation }\end{array}$} & \multirow[t]{2}{*}{$\begin{array}{l}\text { Std. } \\
\text { Error } \\
\text { Mean }\end{array}$} & \multicolumn{2}{|c|}{$\begin{array}{l}\text { 95\% Confidence } \\
\text { Interval of the } \\
\text { Difference }\end{array}$} & & & \\
\hline & & & & & Lower & Upper & & & \\
\hline $\begin{array}{l}\text { Pair } \\
1\end{array}$ & $\begin{array}{l}\text { Skill Test score } \\
\mathrm{T}_{1} \text { acquisition } \\
@ \text { day } 2 \text { - Skill } \\
\text { Test score } \mathrm{T}_{2} \\
\text { retention @ } 1 \\
\text { month }\end{array}$ & 14.667 & 19.384 & 3.539 & 7.428 & 21.905 & 4.144 & 29 & .000 \\
\hline $\begin{array}{l}\text { Pair } \\
2\end{array}$ & $\begin{array}{l}\text { Skill Test score } \\
\mathrm{T}_{2} \text { retention @ } \\
1 \text { month - Skill } \\
\text { Test score } \mathrm{T}_{3} \\
\text { retention @ } 3 \\
\text { months }\end{array}$ & 7.333 & 22.273 & 4.066 & -.984 & 15.650 & 1.803 & 29 & .082 \\
\hline
\end{tabular}

Table 3: Eta squared statistics showing effect sizes

\begin{tabular}{|l|l|l|}
\hline $\mathbf{t}^{2} \div\left[\mathbf{t}^{2}+(\mathbf{n}-\mathbf{1})\right]$ & Eta squared Result & Effect Size \\
\hline $4.144^{2} \div\left[4.144^{2}+(30-1)\right]$ & 0.372 'Pair 1' & Large effect \\
$1.803^{2} \div\left[1.803^{2}+(30-1)\right]$ & 0.101 'Pair 2' & Moderate effect \\
\hline
\end{tabular}

\subsection{Interpretation of Output from Paired-Samples T-Test for Knowledge Assessment}

Table 4 shows the mean performance scores for the 30 wind technicians. Paired-samples ttest (see Table 5) shows the impact of non-practice on technicians' mean scores on knowledge assessment from acquisition Time $T_{2}$ (peak acquisition) ( $M=96.83, S D=4.044$ ) to retention Time $T_{3}$ at one month $(M=80.53, S D=9.187), t(29)=9.037$, Sig. $(p) 0.00<0.05$ (two-tailed). The mean difference in knowledge retention test scores was 16.30 with a $95 \%$ confidence interval ranging from 12.61 to 19.99 . The eta squared statistics 0.738 indicated a large effect size; see Table 6. 
Table 4: Mean knowledge performance score for 30 wind technicians

\begin{tabular}{|l|r|r|r|}
\hline \multicolumn{1}{|c|}{ Knowledge Test Score } & Mean & Std. Deviation & N \\
\hline $\mathrm{T}_{0}$ pre-acquisition @ day 1 & 59.17 & 14.937 & 30 \\
$\mathrm{~T}_{1}$ acquisition @ day 1 & 91.5 & 8.701 & 30 \\
$\mathrm{~T}_{2}$ acquisition @ day 2 & 96.83 & 4.044 & 30 \\
$\mathrm{~T}_{3}$ retention @ 1 month & 80.53 & 9.187 & 30 \\
$\mathrm{~T}_{4}$ retention @ 3 months & 80.43 & 11.575 & 30 \\
\hline
\end{tabular}

Paired-samples t-test (see Table 5) conducted to evaluate the impact of technicians' nonpractice on knowledge test indicate retention Time $T_{3}$ at one month ( $M=80.53, S D=9.19$ ) and retention Time $\mathrm{T}_{4}$ at three months $(\mathrm{M}=80.43, \mathrm{SD}=11.58), \mathrm{t}(29)=0.062$, Sig. (p) $0.951>$ 0.05 (two-tailed). The mean decrease in knowledge retention test scores was 0.100 with a $95 \%$ confidence interval ranging from -3.182 to 3.382 . The eta squared statistics 0.00013 indicated an extremely small effect size; see Table 6.

Table 5: Paired Samples Test for Knowledge Test

\begin{tabular}{|c|c|c|c|c|c|c|c|c|c|}
\hline & \multicolumn{5}{|c|}{ Paired Differences } & \multirow[t]{3}{*}{$\mathrm{t}$} & \multirow[t]{3}{*}{$d f$} & \multirow{3}{*}{$\begin{array}{c}\text { Sig. } \\
(2- \\
\text { tailed })\end{array}$} \\
\hline & & \multirow[t]{2}{*}{ Mean } & \multirow[t]{2}{*}{$\begin{array}{c}\text { Std. } \\
\text { Deviation }\end{array}$} & \multirow[t]{2}{*}{$\begin{array}{l}\text { Std. } \\
\text { Error } \\
\text { Mean }\end{array}$} & \multicolumn{2}{|c|}{$\begin{array}{l}\text { 95\% Confidence } \\
\text { Interval of the } \\
\text { Difference }\end{array}$} & & & \\
\hline & & & & & Lower & Upper & & & \\
\hline $\begin{array}{l}\text { Pair } \\
1\end{array}$ & $\begin{array}{l}\text { Knowledge Test } \\
\text { score } T_{2} \\
\text { acquisition @ } \\
\text { day } 2 \text { - } \\
\text { Knowledge Test } \\
\text { score } T_{3} \\
\text { retention @ } 1 \\
\text { month }\end{array}$ & 16.300 & 9.879 & 1.804 & 12.611 & 19.989 & 9.037 & 29 & .000 \\
\hline $\begin{array}{l}\text { Pair } \\
2\end{array}$ & $\begin{array}{l}\text { Knowledge Test } \\
\text { score } \mathrm{T}_{3} \\
\text { retention @ } 1 \\
\text { month - } \\
\text { Knowledge Test } \\
\text { score } \mathrm{T}_{4} \\
\text { retention @ } 3 \\
\text { months }\end{array}$ & .100 & 8.790 & 1.605 & -3.182 & 3.382 & .062 & 29 & .951 \\
\hline
\end{tabular}

Table 6: Eta squared statistics showing effect sizes

\begin{tabular}{|l|l|l|}
\hline $\mathbf{t}^{\mathbf{2}} \div\left[\mathbf{t}^{\mathbf{2}}+(\mathbf{n}-\mathbf{1})\right]$ & Eta squared Result & Effect Size \\
\hline $9.037^{2} \div\left[9.037^{2}+(30-1)\right]$ & 0.738 'Pair 1' & Large Effect \\
$0.062^{2} \div\left[0.062^{2}+(30-1)\right]$ & 0.00013 'Pair 2' & Very Small Effect \\
\hline
\end{tabular}




\section{CONCLUSIONS}

This study was motivated as a result of practical problems associated with the retention of the work at height and rescue skills after periods of non-routine practice or lack of timed refresher training within the wind industry. It was recognised that technicians registered on the rescue and evacuation refresher training struggle to remember much of the skills they learned after a period of 24 months which is the recommended timeframe for revalidation. Although the work at height rescue and evacuation practice is non-routine; wind technicians are however expected to correctly execute a 'live' rescue if an accident in a dynamically changing environment occurs. Kluge et al. (2009) identified that several accident reports in Europe and USA are associated to the risk of operator errors resulting from increases in nonroutine situations which have some similarity to this study involving rescue and evacuation. Industries such as aviation, nuclear power plants and refineries with highly automated operations counter skill decay with refresher or recurrent training by asserting that refresher training is mandatory and these are regulated by law (Casner et al. 2013). This is apparent because some form of skill rehearsal can moderate skill decay during longer periods of non-use (Patrick, 1992). Also, several authors (Arthur et al. 2007; Arthur Jr, et al. 2010; Kluge \& Frank 2014; Arthur Jr, et al. 2013) have alluded to the issues of skill decay and rates of decay and fundamentally, the work of Hermann Ebbinghaus (1885) republished in Annals of Neuroscience, Ebbinghaus (2013).

The results for the paired samples t-test at acquisition and one month retention for wind technicians show that there was a statistically significant decline in mean performance score with a mean difference of 14.67. This confirms that height safety and rescue skills actually decay within four weeks after acquisition. The skill decay between one and three months was however, gradual over time with a mean difference of 7.43. Adopting the limit state performance' of $70 \%$ as a benchmark of good practice (Lawani et al. 2015); the mean performance score at one and three months for skill assessment was found to fall below this standard which confirms that technicians will struggle to sustain their skill performances up to three months without any form of practice. This shows that non-routine height safety and rescue skills that are discrete and procedural when not practiced over a short or extended period of time are difficult to retrieve. The power law of forgetting confirms that over time, what is known decays at a negatively accelerating pace (Wixted \& Ebbesen 1991; Wixted 2004).

Table 4 with the mean knowledge performance scores for 30 technicians shows the decay of knowledge from $97 \%$ during acquisition to $81 \%$ at one month retention. This represents $16 \%$ change in mean knowledge performance retention at one month. The knowledge decay between one and three months was very gradual with a mean difference of $0.1 \%$, see Table 4. Implementing the 'limit state performance' of $70 \%$ as a benchmark of good practice show that the performance score at one and three months were both higher than this standard. 
This confirms that knowledge can potentially be retained longer than skills and technicians are capable of maintaining their knowledge base longer than three months, (Lawani et al. 2015). However, a reliance only on high knowledge performance score gives a false sense of security in terms of overall procedural competence of wind technicians.

One of the main issues of skill and knowledge retention, whether direct or an intervening variable, is the timeframe between initial training and practice. Therefore, the longer the time interval between training, practice and performance; the greater will be the skill decay. Wixted \& Ebbesen (1991) and Driskell et al. (1992) identified this pattern to appear to be consistent across a variety of skills and tasks. Procedural tasks account for a significant proportion of wind technicians height safety and rescue skills, and the findings reveal that technicians often struggle to retain much of what they have learnt after the training as a result of the complexity of the different rescue and evacuation devices, amount and quality of initial training, length of time of non-routine practice of the rescue devices, and amount and quality of experience acquired on-the-job.

Another factor linked with technician's skill retention is that several types of equipment used during skill training are similar, but sometimes not entirely same to the equipment the technicians are provided on every job. Therefore, in addition to memory loss, rescue performance may be further degraded if technicians have difficulty transferring rescue skills learned during training to slightly different equipment design provided on the job. One way of countering the loss of this rescue skill is by developing a standardised 'device-specific' training and instructional resources that are more resistant to forgetting and more likely to promote transfer of skills to similar tasks and devices; see (Whitehill \& Ellis 1995). Discrete skills that are amenable to deliberate practice but infrequently practiced can decay at an astonishing rate (Ericsson 2004). Frequently practiced skills will help the technician's performance remain consistent while skills of higher complexity with limited opportunities for workplace practice such as the non-routine practice of the height safety and rescue will degrade in the absence of refresher practice (Sauer et al. 2008; Kluge et al. 2010; Lawani et al. 2014).

The peripatetic work pattern of wind technicians also inhibit them from embarking on deliberate rescue practice. Hence, stable deliberate practice of rescue and evacuation with extended experience can further improve performance (Kluge et al. 2009; Kim et al. 2013). Therefore, it can be said that practice brings improvement, and more practice brings more improvement while non-practice brings no improvement.

This study also identified that the devices mostly used for rescue and evacuation (e.g. Constant Rate Descender RG9A and RG10A, Skylotec's Milan 2.0 Hub and Milan 2.0 Rapid Hub, Tractel's Derope Up E, DBI-Sala's Rollgliss R500 Descender) do not have task steps that are cued by the previous sequence of steps or by the rescue equipment, making technicians 
to easily forget these procedural steps and the safety critical steps that are intrinsic to the device. The use of the rescue device deteriorates rapidly because of the obvious lack of internal logic which is associated to discrete procedural tasks involving a number of task steps. Since safe working requires robust procedures to be firmly in place, this paper suggest that training and practice which are contributory factors influencing height safety and rescue skills should be validated early by employers to avoid major incident. Also, the design of the rescue devices should be intuitive, easy to learn, have fewer task steps and easy to execute. Due to non-routine practice and lack of experience, rescue technicians are more likely to make poor decisions which can adversely impact and endanger the safety of casualty needing rescue.

\section{IMPACT OF STUDY TO THEORY AND PRACTICE}

This study can be contrasted with other procedural learning literatures that are more laboratory-based and involving non-end-users of the trained skills. This research instead, examined real life technicians that were involved in hands-on practice (SJT and JKT) over a three month timeframe to assess their proficiency. Therefore, it can be concluded that: the decay of skills take place rapidly within the first four weeks after acquisition and then subsequently gradual; job knowledge is more resistant to decay as compared to rescue skill over the three months study timeframes for technicians; the lack of non-routine practice of these skills lead to decay and there should be a refresher practice drill which is mandatory in order to sustain competency; the rescue device is considered as being deployed and contaminated if taken out of the airtight storage barrel and therefore limits the technicians using it for mock rescue purposes. The wider impact of this study is the ability to replicate it in other work at height related activities involving rescue and evacuation of workers. This can be implemented in work related activities where there are infrequent practices or nonuse of the acquired rescue skills e.g. tower crane rescue, rescue of workers from overhead power lines, and industrial climbing and rigging for the telecommunications industry.

There are certain skills that are reinforced by daily practice and use (e.g. the daily use of lifttruck which consolidates initial training) while some specialised skills are required during cases of emergencies e.g. wind turbines rescue. In this type of scenario, it becomes imperative for organisational and managerial involvement to show consistency in proactive decision making, communicate meaningfully, and allocate time and resources to enhance training and development of the workforce. Failure to identify and address problems in realtime (proactive) regarding the need for competency assessment, worker reviews and training can facilitate the decay of such procedural skills. Also, organisations with no drive for engagement and poor line management can potentially kill off enthusiasm and the need to encourage and promote workforce skill and knowledge assessments and trainings. Therefore, joint and consequential failure of leadership and management can be contributory factors to workforce skill and knowledge decay. 


\section{FUTURE STUDY}

Many organisations do not have the practicality to run regular, life-sized rescue and emergency simulations. However, the advent of digital technologies and its affordability has further enhanced the possibilities of virtual reality simulations e.g. in aviation for pilot training and practice, Formula1, and surgeons using model-based simulators to practice medical procedures. Within the construction, maintenance and utility industry where rescue and evacuation are non-routine, virtual reality e-practice can be used to simulate real-life situations. It can be used to simulate the way the rescue devices operate; replicate humanmachine interactions and behaviours, and used as intervention training by recreating the rescue devices or systems. This virtual reality e-practice technique has the capability of allowing technicians to learn mechanisms and processes that are physically demanding and difficult to execute under certain conditions without actually putting themselves through any sort of danger, thereby mitigating the effects of skill decay in a cost-effective safe way.

Occupational Safety and Health (OSH) issues continue to dominate discussions within the construction and maintenance industry. The application of this type of technology can improve OSH performance, in the same way that other digital technologies are improving wider OSH performance e.g. Building Information Modelling (BIM), use of drones for virtual inspections in high hazard environments, and other simulations e.g. the Hololens headset trialled by Skanska. Virtual reality e-practice has the ability to improve the management of skill decay not only in relation to work at height risks, but also issues such as manual handling, confined space working, machine operations, and hazardous substances (COSHH), where 'low frequency - high impact' incidents may occur.

\section{REFERENCE LIST}

Anderson, G., Hughes, C., Patterson, D. \& Costa, J., 2017. Enhancing inter-professional education through low-fidelity simulation. British Journal of Midwifery, 25(1), pp. 52-58.

Anderson, J. R., 1983. The architecture of cognition. Cambridge, MA: Harvard University Press.

Anderson, J. R., 1993. Rules of the Mind. Hillsdale, NJ: Lawrence Erlbaum Associates.

Arthur Jr., . W., Benneth Jr., W., Day, E. A. \& McNelly, T. L., 2002. Skill Decay: A comparative assessment of training protocols and individual differences in the loss and reacquisition of complex skills, Mesa AZ: AFRL.

Arthur, Jr, W. et al., 2010. The Effect of Distributed Practice on Immediate Posttraining, and LongTerm Performance on a Complex Command-and-Control Simulation Task. Human Performance, Volume 23, pp. 428-445.

Arthur, Jr, W., Day, E. A., Bennett, Jr, W. \& Portrey, A. M., 2013. Individual and Team Skill Decay: The Science and Implications for Practice. New York: Routledge.

Arthur, J. W. et al., 2007. Decay, Transfer, and Reacquisition of a Complex Skill: An Investigation of Practice Schedules, Observational Rehearsal, and Individual Differences, Woburn, MA: Aptima, Inc.. 
Burke, L. A. \& Hutchins, H. M., 2007. Training transfer: An integrative literature review. Human Resource Development Review, 6(3), pp. 263-296.

Burt, C. D., Sepie, B. \& McFadden, G., 2008. The development of a considerate and responsible safety attitude in work teams. Safety Science, Volume 46, pp. 79-91.

Cameron, I., Hare, B., Duff, R. \& McNairney, F., 2011. Using pictures in training: The impact of pictorial OSH training on migrant worker behaviour and competence, Leicestershire, UK: IOSH.

Cannon-Bowers, J. A., Rhodenizer, L., Salas, E. \& Bowers, C. A., 1998. A framework for understanding pre-practice conditions and their impact on learning. Personnel Psychology, 51(2), pp. 291-320.

Carlson, R. A., Khoo, B. H., Yaure, R. G. \& Schneider, W., 1990. Acquisition of a problem-solving skill: Levels of organization and use of working memory. Journal of Experimental Psychology: General, 110(2), pp. 193-214.

Casner, S. M., Geven, R. W. \& Williams, K. T., 2013. The effectiveness of airline pilot training for abnormal events. Human Factors, 55(3), pp. 477-485.

Clarke, N., 2002. Job/work environment factors influencing training effectiveness within a human service agency: Some indicative support for Baldwin and Fords' transfer climate construct. International Journal of Training and Development, 6(3), pp. 146-62.

Dainty, A., Moore, D. \& Murray, M., 2006. Communication in Construction: Theory and practice. London: Taylor \& Francis.

Delaney, P. F., Reder, L. M., Staszewski, J. J. \& Ritter, F. E., 1998. The strategy-specific nature of improvement: the power law applies by strategy within task. Psychological Science, 9(1), pp. 1-7.

Driskell, J. E., Willis, R. P. \& Copper, C., 1992. Effect of overlearning on retention. Journal of Applied Psychology, Volume 77, pp. 615-622.

Ericsson, A. K., 2004. Deliberate Practice and the Acquisition and Maintenance of Expert Performance in Medicine and Related Domains. Academic Medicine, 79(10), pp. S70-S81.

Farrell, P., 2011. Writing a Built Environment Dissertation: Practical guidance and examples. Chichester: Wiley-Blackwell.

Goldberg, S. L., Drillings, M. \& Dressel, J. D., 1981. Mastery Training: Effect on Skill Retention, Alexandria, VA: ARI.

Hare, B. \& Cameron, I., 2011. Site manager safety training. Engineering, Construction and Architectural Management, 18(6), pp. 568-578.

Hatala, R. et al., 2014. Feedback for simulation-based procedural skills training: a meta-analysis and critical narrative synthesis. Adv Health Sci Educ Theory Pract., 19(2), pp. 251-272.

Hirumi, A., 2002. The design and sequencing of E-learning interactions: A grounded approach. International Journal on E-learning, 1(1), pp. 19-27. 
Kim, J. W., Koubek, R. J. \& Ritter, F. E., 2007. Investigation of Procedural Skills Degradation from Different Modalities. Oxford, UK, Taylor \& Francis/Psychology Press, pp. 255-260.

Kim, J. W., Ritter, F. E. \& Koubek, R. J., 2013. An Integrated Theory of Skill Acquisition and Retention in the Three Stages of Learning. Theoretical Issues in Ergonomics Science, Volume 14, pp. 22-37.

Kluge, A. \& Frank, B., 2014. Counteracting skill decay: four refresher interventions and their effect on skill and knowledge retention in a simulated process control task. Journal of Ergonomics,, 57(2), pp. 175-190.

Kluge, A., Sauer, J., Burkolter, D. \& Ritzmann, S., 2010. Designing Training for Temporal and Adaptive Transfer: A Comparative Evaluation of Three Training Methods for Process Control Tasks. Journal of Educational Computing Research, Volume 43, p. 327-353.

Kluge, A., Sauer, J., Schuler, K. \& Burkolte, D., 2009. Designing Training for Process Control Simulators: A Review of Empirical Findings and Current Practices. Theoretical Issues in Ergonomics Science, Volume 10, p. 489-509.

Lawani, K., Hare , B. \& Cameron, I., 2015. Scheduling refresher-based rescue and evacuation training for wind turbine technicians. Vancouver, Canada, The University of British Columbia, pp. 1117-1126.

Lawani, K., Hare, B. \& Cameron, I., 2014. Wind turbine rescue: Emerging skill retention issues and challenges. Portsmouth, UK, Association of Researchers in Construction Management, pp. 11951204.

Lee , F. J. \& Anderson, J. R., 2001. Does learning a complex task have to be complex? A study in learning decomposition. Cognitive Psychology, 42(3), pp. 267-316.

Lievens, F. \& Patterson, F., 2011. The Validity and Incremental Validity of Knowledge Tests, LowFidelity Simulations, and High-Fidelity Simulations for Predicting Job Performance in Advanced-Level High-Stakes Selection. Journal of Applied Psychology, 96(5), pp. 927-940.

Lievens, F., Peeters, H. \& Schollaert, E., 2008. Situational judgment tests: a review of recent research. Personnel Review, Volume 37, pp. 426-441.

Lievens, F. \& Sackett, P. R., 2012. The Validity of Interpersonal Skills Assessment Via Situational Judgment Tests for Predicting Academic Success and Job Performance. Journal of Applied Psychology, 97(2), p. 460-468.

Logan, G. D., 1988. Toward an instance theory of automatization. Psychological Review, 95(4), pp. 492-527.

Macnamara, B. N., Hambrick, D. Z. \& Oswald, F. L., 2014. Deliberate Practice and Performance in Music, Games, Sports, Education, and Professions: A Meta-Analysis. Psychological Science, Volume 25 , p. $1608-1618$.

McDaniel, M. A., Hartman, N. S., Whetzel, D. L. \& Grubb, W. L., 2007. Situational judgment tests, response instructions, and validity: A meta-analysis. Personnel Psychology, Volume 60, p. 63-91. 
Meador, D. P. \& Hill, R. R., 2011. Modeling Training Effects Using a Human Performance Taxonomy. Human Factors and Ergonomics Society, 53(4), pp. 391-402.

Motowidlo, S. J., Dunnette, M. D. \& Carter, G. W., 1990. An alternative selection procedure: The lowfidelity simulation. Journal of Applied Psychology, 75(6), pp. 640-647.

Newell, A. \& Rosenbloom, P. S., 1981. Mechanisms of skill acquisition and the law of practice. In: J. R. Anderson, ed. Cognitive skills and their acquisition. Hillsdale, NJ: Erlbaum, pp. 1-56.

Pallant, J., 2011. SPSS Survival Manual: A step by step guide to data analysis using SPSS. 4th ed. New South Wales: Allen \& Unwin.

Patrick, J., 1992. Training: Research and Practice. San Diego, CA: Academic Press.

Patterson, F., Zibarras, L. \& Ashworth, V., 2016. Situational judgement tests in medical education and training: Research, theory and practice: AMEE Guide No. 100. Medical Teacher, 38(1), pp. 3-17.

Paulin, C., McKee, A. F., Hanon, M. A. \& Hedge, J. W., 2002. Development of criterion measures to assess retention and decay of aerospace physiology knowledge and skills, Mesa, AZ:: Human Effectiveness Directorate..

Ployhart, R. E. \& Vandenberg, R. J., 2010. Longitudinal Research: The theory, design, and analysis of change. Journal of Management, Volume 36, pp. 94-120.

Sabol, M. A. \& Wisher, R. A., 2001. Retention and reacquisition of military skills. Military Operations Research, 6(1), pp. 59-80.

Salas, E., Wilson, K., Priest, H. \& Guthrie, J., 2006. Design, delivery, and evaluation of training systems. In: G. Salvendy, ed. Handbook of human factors and ergonomics. 3rd ed. Hoboken, NJ: John Wiley \& Sons., pp. 472-512.

Sauer, J., Hockey, G. R. J. \& Wastell, D. G., 2000. Effects of training on short- and long-term skill retention in a complex multiple-task environment. Ergonomics, Volume 43, p. 2043-2064.

Schendel, J. D. \& Hagman, J. D., 1982. On Sustaining Procedural Skills Over a Prolonged Retention Interval. Journal of Applied Psychology, Vol. 67, No. 5, pp. 605-610.

Shields, J. L., Goldberg, S. L. \& Dressel, D. J., 1979. Retention of basic soldiering skills, Alexandria, VA: U. S. Army Research Institute for the Behavioural and Social Sciences.

Stothard, C. \& Nicholson, R., 2001. Skill Acquisition and Retention in Training: DSTO Support to the Army Ammunitions Study, Edinburgh South Australia: DSTO Electronics and Surveillance Research Laboratory.

Teachout, M. S., Winston, B. J. R., Barham, B. \& Phalen, W. J., 1993. Determining Intervals for Aerospace Physiology Refresher Training: An Approach for Research. Williamsburg, Virginia, Military Testing Association, pp. 456-461.

Trochim, W. M. K., 2005. Research Methods: The Concise Knowledge Base. s.l.:Atomic Dog Pub. 
Weekley, J. A., Ployhart, R. E. \& Holtz, B. C., 2006. On the development of situational judgment tests: Issues in item development, scaling, and scoring. In: J. A. Weekley \& R. E. Ployhart, eds. Situational Judgment Tests: Theory, Measurement and Application. San Francisco, CA: Jossey-Bass, pp. 157-182).

Weissbein, D. A., Huang, J. L., Ford, J. K. \& Schmidt, A. M., 2010. Influencing learning states to enhance trainee motivation and improve training transfer. Journal of Business and Psychology, Volume 26, pp. 423-435.

Whitehill, B. V. \& Ellis, J. A., 1995. The Effect of Qualitative Explanations and Pictures on Learning, Retention, and Transfer of Procedural Tasks, San Diego, California: NPRDC.

Wixted, J. T., 2004. The psychology and neuroscience of forgetting. Annual Review of Psychology, Volume 55, pp. 235-269.

Wixted, J. T. \& Ebbesen, E. B., 1991. On the form of forgetting. Psychological Science, Vol. 2, No. 6, pp. 409-415. 